https://doi.org/10.24101/logos.2017.74

Gauta 20171122

\title{
VIDA SAVONIAKAITÉ
}

Lietuvos istorijos institutas

Lithuanian Institute of History

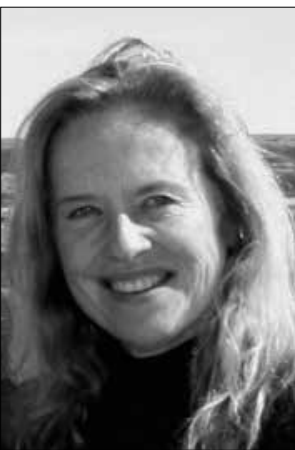

\section{ESU LIETUVIS PASIENYJE}

\section{Lithuanian on Borderland}

\author{
SUMMARY
}

Contemporary communities contain 'multivocal' notions of people. To people who support multicultural policies and other ideas of post-industrial polyethnic states, ethnicity has become less important. The individual opinions are controversial. The changing relationship between ethnic, cultural and national identity in Europe and beyond has given rise to ongoing discussion in anthropological theory. Under conditions of globalization, we come across what theorists call 'cross-border', 'situational' ethnicity, 'narrative' identity. What are the consequences of this weakening factor of being on borderlands? I argue that the coexistence of different ethnic groups inspires the securitisation. The paper will discuss the theoretical approaches and the different cases of changing notions of belonging, of "them and us" and correlated roots of insecurity on Lithuania's borderlands during 2000-2017. By a constructivist approach the paper will compare the interdisciplinary notions of belonging with inter-cultural networks of the political demands of modern societies and concepts of Lithuanianness. The focus is on small communities and individuals in history on the borderlands of West, North, and East Lithuania.

\section{SANTRAUKA}

Šiuolaikinių bendruomenių nacionalumą atskleidžia "daugiabalsès" žmonių sampratos. Daugeliu atvejų etniškumas tapo ne toks svarbus žmonėms, kurie palaiko multikultūrinę politiką ir kitas postindustrinės polietninės valstybės idèjas. Individualūs požiūriai yra kontroversiški. Kintanti etninės, kultūrinės ir nacionalinės tapatybės Europoje priklausomybè skatina šiuos klausimus nagrinèti teoriniais antropologiniais ir tarpdalykiniais požiūriais. Globalizacijoje ir migracijoje matome "tarpvalstybinį", „situacinį" etniškumą, "naratyvų" tapatybę. Kokios silpnėjančių priklausymo tautai, "jų ir mūsų" sampratų pasekmės? Keliu hipotezę, kad skirtingi žmonių „saugumo pojūčiai“ priklauso nuo etninių grupių bendrabūvio istorijoje. Straipsnyje nagrinėjami teoriniai ir skirtingi besikeičiantys nacionalumo, nesaugumo realijų atvejai Lietuvos pasieniuose 2000-2017 m. Daugiausia aptariami klausimai: kaip pasieniuose lietuviai nusako savo ir Kito nacionalumą, tapatybes, šiuolaikiniais akademiniais terminais tariant, priklausomybę tautai? Kokios istorinès 
realijos glūdi sava / svetima, namai / kita sampratose? Kaip skiriasi etninių grupių požiūriai? Ar šiame migracijos amžiuje dar svarbi lietuviams etnografinė priklausomybė? Kokios kultūrinės vertybès siejasi su saugumo jausmu žmonių nacionalumo sampratose?

\section{IVADAS}

Žmonių saugumas mokslininkų aptariamas kaip tarpkultūrinio sutarimo vertybè. Zygmundo Baumano teigimu, „kuo daugiau imigrantai jaučia, kad ju prigimtinès kultūros tradicijos yra gerbiamos adaptuotoje valstybejje, tuo mažiau jie nemėgsta, nekenčia, atmeta, bijo, kovoja prieš skirtingas tapatybes; kuo patrauklesnès naujosios šalies kultūrinès galimybès, tuo mažiau imigrantai atsiskiria visuomenèje ${ }^{\prime 1}$. Šios idèjos siejasi su etniniu istoriniu procesu problematika, integracija, kerštu, tarpininkavimu, valstybingumu izvairiuose pasaulio regionuose $^{2}$. Taip pat, mano tyrimu duomenimis, pasienyje tapatybès yra „instrumentalios", „situacinès" ir iš naujo konstruojamos "naratyvu“", kai Lietuvos pasienyje politinès ar kitos aplinkybès sukelia kultūros dichotomijas ${ }^{3}$. Žvelgdami i šiuos procesus nuodugniau ir plačiau, prisiminkime Z. Baumano interpretacija, kad esame „istorijos dariniai, kadangi kuriame istorija sąmoningai ar ne. Mūsu valia ieškoti atsakymu, tiek veiksmais, tiek ir žodžiais ${ }^{\prime 4}$. Šiuo straipsniu siekiu atskleisti, kaip 2000-2017 m. migruojantys lietuviai valstybės pasieniuose identifikuoja savo tautines, etnines, kultūrines, teritorines tapatybes ir kartu saugaus bendrabūvio vertybes. Daugiausia domèsiuosi klausimais: kaip pasieniuose lietuviai nusako savo ir Kito nacionaluma, tapatybes ar, šiuolaikiniais akademiniais terminais tariant, priklausomybę tautai? Kokios istorinès realijos susijusios su sampratomis sava / svetima, namai / kita? Kaip skiriasi etninių grupių požiūriai? Ar šiame migracijos amžiuje dar svarbi lietuviams etnografine priklausomybė? Kokios kultūrinès vertybės siejasi su saugumo jausmu žmonių nacionalumo sampratose?

Teorinis šio tyrimo pagrindas yra Z. Baumano idëja, kad egzistuoja griežta koreliacija tarp nesuprastos grèsmès ir problemiškų kultūrinių skirtumu „nuginklavimo“. Nesantaiką tarpkultūriniuose dialoguose gali sukelti iveikti kultūrinio separatizmo impulsai. Šių problemu sprendimas - tai „bendros žmonijos ieškojimas ${ }^{\prime 5}$.

Interpretuojant $Z$. Baumana, pirmiausia "būti nestabiliam" - tai kalbèti apie „jų ir mūsų" reikšmes. Be to, „būti nestabiliam" galima suvokti kaip jègos ir veiksmo asimetriją: ,jie gali, o mes negalime“... Mes priklausome nuo tos malonès ịvairiais savo pragyvenimo aspektais ir pan. Apibréžimas paremtas Martino Heideggerio, Jean-Paulio Sartre'o atliktais tyrimais ${ }^{6}$. Svarbu pažymèti, kad etnografinius tyrimus mokslininkai laiko labai svarbiais šiai problematikai analizuoti. Akcentuojama atstumo tarp tyrejo ir tyrinejamu subjektų reikšmè.

Akademiniuose debatuose "saugumo" (securitisation) terminas pasirodè visiškai neseniai. Z. Baumano teigimu, šis svarbus terminas reiškia suvokti ir apibūdinti, dažnai perklasifikuoti „nesaugumo" pavyzdžius?. Pasak Andreas Rauho, 
„kultūra" ir "tarpkultūriškumas“ šiuolaikinëje migracijos eroje siejama su ,,saugumo studijomis" (security studies) ${ }^{8}$. Ieškoma svetimo ribų ir reikšmių.

Apibendrindami ankstesnius etnologu darbus, skirtus Lietuvos pasienio bendruomeniu nacionalumo analizei, visų pirma išskirkime $1998 \mathrm{~m}$. paskelbtą Petro Kalniaus minti̇, kad Lietuvos tautinių mažumų pilietinès bei kultūrinès integracijos i Lietuvos visuomenę problemos susijusios su gana dideliu etniniu bendruomenių vidiniu kultūriniu uždarumu. Panašios problemos būdingos beveik visoms Rytu Europos šalims 9 . Priešingai, $2005 \mathrm{~m}$. daug Lietuvos-Latvijos pasienio ruožo lietuviu pasak Sauliaus Sužiedèlio, Irenos Reginos Merkienès, buvo autochtonai ir palankiomis sąlygomis puoselëjo savo kultūrą ${ }^{10}$.

Antra, istoriniai įvairiu etniniu grupių mentaliniai žemèlapiai, remiantis Dariaus Staliūno ir kitų tyrimais, atskleidžia skirtingas Lietuvos sampratas ${ }^{11}$. Šiuolaikinis gyvenimas Pietryčiu Lietuvos pasienyje, Dariaus Daukšo teigimu, leidžia palaikyti ìvairialypi Lietuvos lenkų ryši su valstybe ar valstybėmis ${ }^{12}$. Mano atliktų etnografinių tyrimų duomenimis, migruojanti visuomene ivvairiai interpretuoja savo nacionalumą, o pasakodama apie "tradicijas“, nusako skirtingu etniniu grupių bendrabūvị.

Trečia, savo ir Kito tyrimų laukas krypo $\mathfrak{i}$ istorinius kultūrinius, regioninius visos Lietuvos ar atskiru etnografiniu regionų savitumus - kultūros reiškinių ir kultūrinių tapatybiu tipus, koreliacija, asimiliaciją ir difuziją ${ }^{13}$. Daugiausia tyrejai domejosi Pietryčių ir Šiaurès Lietuvos pasieniu. Akivaizdu, savo ir Kito vaizdiniai, kultūra, nacionalumas etnologu mažai atskleisti platesniu migruojančių ìvairių etninių grupių požiūriu.

Mokslo darbai ir mano naujausi etnografiniai tyrimai rodo, kaip Pietryčiu Lietuvos pasienių bendruomenès išsiskiria uždarumu, Pietryčių Latvijos pasienio - lietuvių autochtonu kultūra, kaip istorijoje pasienių erdvė keičiasi, kultūra igyja naujų reikšmių; jų visų sykiu neapimsime, o šiame straipsnyje analizuosime mažiau ištirtas Šiaurès, Vakaru ir Rytu Lietuvos bendruomenes, remdamiesi migrantų požiūriais. Keliu hipotezę, kad skirtingi žmonių "saugumo pojūčiai" priklauso nuo etniniu grupių bendrabūvio istorijoje. Nagrinèsiu: 1) teorines etnografijos prielaidas; 2) migruojančiu žmonių požiūrius i namus / kita; 3) skirtingu tautu "namu“ sampratas; 4) maišytų etninių ir teritorinių grupių bendrabūvị; 5) "saugumo pojūčius“ ir nacionalumą pasienyje.

Konstruktyviu lyginamuoju teoriniu požiūriu atskleisiu, kaip Lietuvos pasienio gyventojai etnografiniuose pasakojimuose nusako nacionalumą, "jų ir mūsų" reikšmes, o kartu ir "saugumo pojūčius". Situacijas naratyvuose lyginsiu su stebėjimų dalyvaujant etnografiniuose tyrimuose ir kt. rezultatais. Sienų režimą suprantame kaip netikètus susitikimus, itampas, konfliktus ir ginčus. Pasieniai taip pat gali būti interpretuojami kaip sienu kirtimas, kaip rezistencijos veiksmai ar kt. ${ }^{14}$, kur tapatybiu sampratos bei savo ir Kito vaizdiniai, mano tyrimų duomenimis, ypač išraiškingi. Pasienius apibūdinsiu kaip daugiakultūrinius savaip lietuviu, ivvairių etniniu grupiu, interpretuojamus "namus“, regionus, vietas. 


\section{TEORINÉS ETNOGRAFIJOS PRIELAIDOS}

Šiuolaikiniu antropologiniu teoriniu požiūriu, kalbant apie etniškumą ir nacionalumą, svarbu pažvelgti i „žmonių balsus iš apačios“. Mokslininkai kritikuoja modernius sukonstruotus tautos kūrimo naratyvus ${ }^{15}$. Amerikiečių ekonomikos antropologo Stepheno Gudemano ir vokiečiu antropologo Chriso Hanno žodžiais, kai kiekvienas tyrejas iš lokalios perspektyvos „veidas i veidą“ (face to face) patiria socialinio gyvenimo kokybę, jis gali atskleisti gyvenimo realybę. Svarbu neiškraipyti ar romantizuoti „holistinio" mažų bendruomenių socialinių ryšiu pobūdžio ${ }^{16}$. Etnografijoje namuose siekiau objektyvumo. Etnografinius tyrimus Latvijoje, Lietuvoje, Lenkijoje, Vokietijoje vykdžiau 1996-2017 m. ${ }^{17}$, trumpai grižždama ị kai kurias vietoves, ilgiau ar trumpiau gyvendama ir stebėdama miestu, miesteliu ir kaimų individus bei bendruomenes. Be to, $1991 \mathrm{~m}$. tyriau lietuviu salas Baltarusijoje, o 2017 m. - Vokietijoje; šiame darbe jie - palyginamieji kaip ,jie ir mes".

Metodologiniu požiūriu, sekant anglu antropologu Timu Ingoldu, švedu antropologe Anne S. Gronseth ir kitais, pranokstatys ribas žodžiai ir vizualiniai stebèjimai sukelia jausmus, skatinančius dalytis patirtimi. Išgyvenant itampą tarp susidūrimu tarp savo ir Kito patirčiu būti šiame pasaulyje, galima rasti etišką požiūrį ir šaltinį, kuris pranoks savą moralę ir sukurs nuoširdų žinių apie Kitą režimąa ${ }^{18}$. A. S. Gronseth teigia:

žmonès ir žinios apie juos yra sudarytos ryšiu tarp savęs ir Kito. Šie yra jau socialiniais vaizdiniais ir jègos ryšiais paveik- ti. Todèl ryšys pats-Kitas taip pat subjektas-intersubjektyvumas yra visuomet istoriškai ypatingas ir igauna išskirtines formas skirtingu laiku. ${ }^{19}$

Pasirinkdama, ką kalbinti, neturiu jokios išankstinės informacijos apie žmogų; pirmiausia stebiu aplinką ir siekiu sutikti įdomių individu, kuriu lytis, amžius, išsilavinimas ir socialiniai interesai būtų kuo įvairesni. Paskui žmonès nurodo savo pasakojimuose kitus įdomius asmenis. Tokiu būdu atskleidžiamos "daugiabalsès" platesnès visuomenès sampratos.

Ieškoma savo, svetimo, Kito ribu ir reikšmiu bendruomenëje bei kultūroje, suteikiančioje ",saugumo“ jausmą. Anthony'io P. Coheno manymu, žmonių vietos jausmas vaizdžiai nusako ju „priklauso-

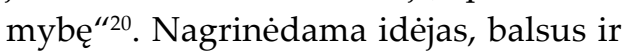
pasakojimus, didžiausią dèmesị kreipiu i žmonių nacionaluma, „namų sampratas ir tarpusavio ryšius bendruomeneje.

Vokiečių tyrëjo Andreas Rauho teigimu, „kultūra“ pati savaime daug reiškianti ir mažai difuzinè. Nacionalinè kultūra laikoma ne tik geografiniu konstruktu, daugiau ìvairiu „,kultūros kambarių rūšimis", kurias galime lyginti su senosios kultūros interpretacijomis Secesijos kultūroje. Siekiama atsekti, kokiai kultūrai priklauso kuris nors reiškinys ${ }^{21}$. Daugelio mokslininku sutarimu, migracijos procesuose iškyla nauji klausimai: koks semiotinis kultūros suvokimas, kokios kalbos formos ${ }^{22}$ bei jų interpretacijos, kaip „saugumo pojūčiai“ geografinèje erdvèje.

Nagrinèju pasienį kaip prieštaringus vaizdingus bendrabūvio atvejus. Etno- 
grafiniai tyrimai daugiausia apima nedidelių miestų ir miestelių ar kaimų realijas. Nuo seno mokslininkų miestietiškomis yra vadinamos „socialinès sąlygos, nurodančios esminius kasdienio gyvenimo îpročius, galvojimo būdus, bendravimą"23. Remdamasi Henri Lefebvre (2003[1970]), Julie-Anne Boudreau teigia, kad miesto gyvenimas yra politinis gy- venimas; miestietišku laikome žmonių savitus „ryšius su erdve, laiku ir mobilu-

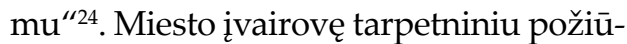
riu tyrinèjo dar Čikagos mokykla ${ }^{25}$, o šiuolaikinė Europos pasienių erdvė, daugelio antropologu sutarimu, ne mažiau svarbi. Todèl pateikiu ilgesnius žmonių pasakojimus, kuriuose bendrabūvis būtų atskleistas „balsais iš apačios".

\section{NAMAI / KITA MIGRUOJANTIEMS}

Monsinjoras kunigas Pranciškus Ščepavičius iš Baisiogalos, gyvenęs ịvairiose vietose Lietuvoje ir tremtyje Sovietu Rusijoje, pasakojo:

Lietuvis, katalikas, 10 metų komunizmą statė šiaurèje lageryje. Pats žemaitis, tuo didžiuojuos. Mano tèveliai žemaičiai. Žemaitija iš istorijos verta pagarbos. Labiausiai priešinosi svetimai iztakai žemaičiai. Savo kalba. Savi papročiai. Papročiai daug nesiskiria. Žemaitijoje negaminamas alus, iki karo negaminama naminè. Aukštaičiai gamino alų, alus kaip Palestinoje duona ir vynas... Didelio skirtumo nerastų. Dirbo Aukštaitijoje, daug kas neįtarè, kad aš žemaitis. Man smagu su žemaičiais pasišnekèti žemaitiškai. Raseiniškiai dūnininkai. Moku moku Douk dunas, douk pyno“... Žinot, ką gi aš mokiausi, vestuvėse, krikštynose nedalyvaudavau - tiesiog nežinau. Seniau nuolatinè daina, einam ị darbą - daina, grižtam iš darbo - daina. Linaminis jaujoje, baisios dulkès - pabaigè darbą ir užtraukė dainą vidury nakties. O gavènioje užgieda, man liepia keltis, o gretimame kaime didelè šeimyna jau dainuoja. Iš ryto eina i darbą ir daina?

Kur gyvenu (Baisiogaloje. - V. S.), čia turètu būti ir mano kapas. Parašiau testamente. Baisiogala atsirado po karo. Čia buvo dvaras ir bažnyčia. Vietoj dvaro kumetynu prie plento pasidarè davatkynas. Kai buvo sodybu griovimo metai daug susikèlè. Čia buvo labai remiamas valstybès tarybinis ūkis. Pristatyta trobesių penkiaaukščių - žmonès subėgo. Komara, kai atejo Raudonoji armija, pasodino i kalèjima, Karagandos srityje mirè. Žmona išvažiavo į Lenkiją... žmonès atsiliepia gana šiltai.

Kultūrinis gyvenimas nyksta... Kultūros namai (sovietmečiu. - V. S.) norèjo nustelbti bažnyčią. Matot, dabar dangus ir žemè - viskas skiriasi... (Monsinjoras kunigas Pranciškus Ščepavičius, g. 1918 m. Konjoju k., nebėra to kaimo, Raseinių valsč., turëjo 20 ha, studijavo Vytauto Didžiojo universitete Teologijos fakultete iki 1945 m. Dirba 25 metus Baisiogaloje. Pasakojo 2004 m., F 73 2307(36).

Monsinjoro teiginys „,kur gyvenu, čia turètų būti ir mano kapas" rodo, kad „namai“ - tai vieta, kur jis gyvena. Pasakodamas apie savo tapatybę, daug istoriju jis siejo su šiais „namais". Ivvairiausių patirčių kentęs, ìvairiose politinèse situacijose dirbęs, išgyvenęs monsinjoras kunigas Pranciškus Ščepavičius šiltai atsiliepia apie žmonių sugyvenimą „tarp savų“. Ši sąvoka „,tarp savų“ pir- 
miausia apima žemaičių istorija, kalbą ir kultūrą - etnografinius kultūrinius jo "prigimtinius" išskirtinumus, ypač svarbius kaip tautos istorijos dalis. Antra, tarp to paties likimo žmonių Sibire jis jautèsi "tarp savų". Trečia, svarbiausia kultūroje - „man smagu su žemaičiais pasišnekèti žemaitiškai“. Ketvirta, nei Sibiro, nei Žemaitijos gimtinès „namų" vaizdiniai nebuvo nusakyti. Monsinjoras gražiai pasakojo apie Baisiogalos žmonių kultūrines „tradicijas". Šias jis siejo su talkomis, bendruomeniškumu. Būtent toks bendruomeniškumas, monsinjoro žodžiais, "pabaigè darbą ir užtraukè dainą vidury nakties", rodo žmonių bendrabūvio darną ${ }^{26}$. Penkta, šiuolaikiniuose etnografiniuose regionuose migravęs ir daug matęs žmogus nesureikšmina lietuvių etnokultūrinių skirtumų, teigia, kad „papročiai daug nesiskiria“. Galiausiai apie Aukštaitijoje gyvenusius įvairių tautybių atstovus ,„žmonès atsiliepia gana šiltai“. Išnagrinètas yra nedidelio miestelio, kuriame industrija ir prekyba apmirusi, atvejis.

\section{"NAMUOSE": SKIRTINGA PRIKLAUSOMYBE் TAUTAI IR ETNOGRAFINIAM REGIONUI}

Kalbeddami apie savo tautybę, Vakarų ir Šiaurès Vakarų Lietuvoje žmonès atskleidžia skirtingu etninių ir tautinių grupių, kartu ir etnografinių bendruomenių, susidūrimus bei kompromisus namuose:

Mama lenkè, tèvas žemaitis - viską žemaitiškai mama išmoko. (Pasakojo vyras iš Kantaučių. VSA TT 18.)

Žemaičiai... iš gretimų kaimų susiženijo. Kalba [žemaitiškai. - V. S] ne kiekvienas žemaitis. I mūsų žemaičių šeimą atkeliavo du lenkai (pase lenkas). Mažeikiškis lenkas šneka žemaitiškai, Trakuose ji vadina žemaičiu. (Pasakojo 1960 m. Šatėse gimusi moteris. VSA TT 32.)

Pateikti pavyzdžiai rodo, kokia svarbi žmonėms yra tos vietovės, kurioje jie gyvena, kalba. Kitų tautybių žmonès, kaip lenkas iš Mažeikių, šneka žemaitiškai. Žinoma, tarmè ne visiems lengvai išmokstama, tačiau lietuviškų miestelių ir mišrių šeimų aplinka skatina ,,sulietuvèti" namuose. Panašias tendencijas matysi- me kitose Europos šalyse. Judith Schlehe pateikia pavyzdžių, kaip mišrios vokiečių-graikų šeimos perima moterų vokiečių tradicijas ${ }^{27}$. Patvirtinama ir žinoma klasikinè anglų antropologo A. Coheno mintis, kad „priklausomybè “ asocijuojasi su vietinèmis teritorinèmis bendruomenemis ${ }^{28}$.

Priešingai, Elena iš Salako, Rytų Lietuvos, kur gyvena daug ivairių etniniu grupių, o teritorijos buvo Lietuvos-Lenkijos pasienyje ${ }^{29}$, teigè:

Sako, lietuvè. Gimè okupuotoje Lenkijos Lietuvoje. Aplink lenkai, o mūsų kaimas lietuviškas, bet mes nemokame gerai kalbèti lietuviškai. Nežinau, gyveno už Dūkšto, netoli nuo Baltarusijos. Mokytojas ateidavo namo iš lietuviškos mokyklos. Jis ateidavo po mokyklos - Nalivaika Bronius. Tẻvas bijojo politikos, buvo Amerikoje. Nebuvo nei partizanu, nei stribų vis tiek septynias šeimas ištrèmè.

Švenčia kaip švenčia bažnyčios. Lenkų viskas tas pats. Taip ir mes švenčiam, mes gi ne maskoliai. Rusai savo laiko. Mažai 
jau yra tokių. Jau dabar nieko nedarom. Jau viskas parduotuvèje... kepèm pirma. Turime ruskaja pečka.

O kaip nebrangi gimtinè... Sako, lietuviškiausia parapija buvo Daugèliškis... Dabar Vydžiai - Belorusija. Mes neidavom į lenkišką, eidavom už upés Daugèliškin... Dabar eina - o kaipgi. Dukra eina labai dažnai (iš Vilniaus). Kaip brangūs namai, kai išvežè... Kolūkis gal buvo, dabar pelkès pasidarè.

Salake gal rusu emigrantu yra. Vietinių mažai. Kai buvo jaunesni sueidavo. Dabar pusę Salako nepažįsta. Daugiausiai - lietuviai. (Elena g. 1929 m. Jenaus k. Dūkšto apylinkèje, lietuvè, baigè Jenave lenku mokyklą - 3 klases, užejjo karas. Turëjo 17 ha. $1958 \mathrm{~m}$. iš Sibiro atvažiavo i Salaką. Pasakojo 2004 m. F 73 2307(59).)

Elenai, kuri buvo prievarta išvežta iš namų, "namai" nepaprastai brangūs ir sieti su "lietuvybe“. Gyvendama nelietuviškoje Rytu Lietuvos bendruomenëje ir aplinkoje, būdama lietuvè „nemoka gerai kalbèti lietuviškai“. Jos gimtinè yra dabartinëje Baltarusijoje, kur lietuviškuose kaimuose gyvenę lietuviai ypač puoselëjo lietuvybę. Tẻvai siekẻ mokyti vaikus lietuviškose mokyklose; ilgus dešimtmečius trukę procesai Rytu ir Pietryčiu Lietuvoje, kur vèliau, Vitalijos Stravinskienès žodžiais, sovietinè valdžia vykdè SSRS pakraščiu homogenizavima, tarpetniniai lietuvių ir lenkų ar lenku ir rusu santykiai buvo itempti ir priešiški, ${ }^{30} \mathrm{o}$ šiuolaikinès visuomenès dar neužmiršti. Moteris nusako, kaip migracija pasienyje keičia bendruomenę.

Skirtingų etniniu grupiu "tradicinius" kultūros ypatumus Elena nusako savitai: „lenku viskas tas pats. Rusai savo laiko". Išskiriami kultūriniai religiniai skirtumai, ugdomi bažnyčios. Tuo tarpu, pasak jos, skirtingu etniniu grupių, gyvenančių viename kaime, kartu nedidelëje bendruomenèje, kultūrinès "tradicijos“ supanašèja. „Modernių“ kultūros elementu atsiranda tradiciniu švenčiu patiekaluose ir pan. Itaigiai nupasakota Salake vykusi migracija. Šis naratyvas itikinamai rodo, kaip lietuvybe sieta ne su „tradicine“ kultūra, o su meile, pagarba ir siekiu išlaikyti savo lietuvišką kalbą "namuose“.

Išskirtiniu atveju ruse moteris iš Juodupès, Šiaurès Rytų Lietuvos, etniškai mišrios, daug migravusios šeimos, laiko save ruse aukštaite, nes gyvena Aukštaitijoje ir šneka ịvairiomis kalbomis:

Stačiatiké-staroverè, rusè. Vyras lietuvis, du vaikai lietuviai, namie kalba lietuviškai. Kokie žmonės yra, su visais sueina... kalba vieną žodị lietuviškai, kitą - rusiškai, sūnus juokiasi, ot pakalbëjo; žmonès tie patys, skiriasi religija.

Aukštaitè, nežinau kaip čia dabar pasakyti, Lietuvoj gimiau ir gyvenu. Miliūnų kaimą prie vokiečiu sudegino. Nieko gero nemačiau - gyvenimas sunkus. Per karą „Nemuną" (fabriką. - V. S.) sudaužè. Tada pastatè nauja, atvežtos naujos mašinos. Seneliai per Pirmajij karą išvažiavo, mama iš Latvijos. Tèvas gyveno Miliūnuose... Mama iš Subatès, yra "vietinè". Ruse iš Latvijos. Brolis Latvijoje apsivedè. Lietuviai nuo mūsų atsiskyrè. Mes einam senybiškai - bažnyčios įstatymų nekeičia. Jaunimas mažai - nelabai kas...

Dabar Juodupès gyventoja. Šaknys Miliūnuose. Kaipgi ne brangi gimtinè? Ten ir žemės yra 8 ha - duktè dirba - sudegino vokiečiai... čia (Juodupè. - V. S.) antra tèviškè.

Senelis buvo kunigu. Tėtė ejo bažnyčion giedojo...

Paska gamino (Velyku patiekalas iš varškès. $-V$. S.). Dabar nelabai. 
Latviai daugiau važinejja... buvo brolienė atvažiavusi. Per Sekmines ejjo ant kapu - savaitę pabuvo. Mes dedam ant kapo kiaušinius, du ar tris, ir pabarsto dèl paukščiukų dažytų. Seniau per Sekmines buvo pilna žmonių; grūdų ịpildavo terbelèn ir duodavo tiems, kurie sèdi... Mama sakydavo, kai nudažysit kiaušinių, pabarstykit ant kapu - nieks nemato, tik paukščiukai atskrenda pas mus palest... Daugiausiai dažydavo raudonai. Raudona surišta su švente. (Pasakojo 2004 m. Miliūnų k., 1928 m. gimusi moteris, nuo 1946 m. gyvenanti Juodupejje, F73 2307(48).)

Moteris iš Juodupès puikiai atskleidžia, kaip plačiai vyko migracija Šiaurès Lietuvos pasieniuose ir kaip stipriai ši migracija paveikè bendrus lietuvių, latvių, rusų ryšius šeimose. Pirmiausia žmonès kalbejjo ịvairiomis kalbomis vienu metu, rinkdamiesi vieną lietuviška, kitą rusišką ar lenkišką žodị ir pan. Galime teigti, kad mišri etninė bendruomenè ivairiuose Lietuvos pasieniuose bendraudama tarpusavyje supina įvairias kalbas. Apie tarpetninius konfliktus jie nekalba.

Gimtinè Miliūnai moteriai yra brangi.

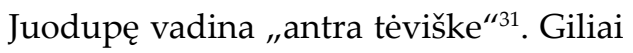
šaknis Lietuvoje įleidusi stačiatikè-sentikẻ rusè, kurios močiutè grižo i̇ Lietuvą, gerai kalbėjo lietuviškai. Ji išlaiko savitas "tradicijas". Jos, taip pat kaip ir Elenos iš Salako, teigimu, "tradicijos" ir ritualai glaudžiai siejami su religija: „mes einam senybiškai - bažnyčios îstatymų nekeičia. Jaunimas mažai - nelabai kas..." Analogiškai šiame visiškai kitame Šiaurès Lietuvos pasienyje "tradiciniai“ ir „modernūs" elementai vienaip interpretuojami vyresniosios kartos, kitaip - jaunesniosios. Mano stebejimai leidžia teigti, kad iš esmès panašių, tik su savitomis detalèmis bei istorijomis, atvejų Lietuvoje daug.

Rusès mama iš Subatès, kuri yra Latvijoje, laikoma „,vietine“. Šiuo atveju skirtingu valstybių pasienyje ryšiai labai glaudūs. „Vietine“" mama gali būti laikoma dèl teritorijos bendrumo bei didelès ekonominès lietuvių migracijos i Latviją buvusioje Sovietų Sajungoje. Šiuolaikiniu teoriniu požiūriu tai būtų ,,tarpvalstybinè ar „situacinè " tapatybè. Pati rusè moteris save vadina aukštaite, nes jos dabartiniai „namai“ yra Aukštaitijos teritorijoje. Palyginkime ši pasakojimą su Nigelio Rapporto teoriniais tyrimais, kad „naratyvais“32 nusakoma tapatybé ilgainiui gali keistis, tačiau ši rusė moteris šiuo metu jaučiasi saugiai bendruomenėje, kurioje puoselèja savo kultūrines tradicijas.

\section{MES MAIŠYTI? TAUTŲ BENDRABŪVIS IR "NAMAI“ PASIENYJE}

Pasak Z. Baumano ${ }^{33}$, svarbu įsidèmèti, kaip pabrèžè vokiečių sociologas Ulrichas Beckas, kad mūsų pasimetimą veikia skirtingas ar, kitaip tariant, vienas kitam prieštaraujantis savęs suvokimas „kosmopolitinèse situacijose“ ir „kosmopolitinis sąmoningumas". Stanislovas iš Žagarès pasakojo:
Čia beveik visi skerslatviai. Tẻvai vietiniai. Čia viskas nuo kalbos. Yra skirtumai. Dukters vyras gražiai kalba, mes maišyti - nei latvis, nei lietuvis, nei žemaitis. Brangi skerslatviu kalba.

Mama buvo mokytoja. Tėtè mirè 1946 m. Mama skubejo atiduoti 14 ha žemès ūkio artelei, parodè pavyzdi kaip kaimo mokytoja, nes grèsė Sibiras. Buvo 
penki vaikai. İ Žagarę atejo pirmieji... čia buvo žydija, čia buvo žydų kino salè - vokiečiai susprogdino, sulygino, pastatè du namus. Visko matem... kai buvo nuosavi ùkiai, vieni kitam padedavom, talkos būdavo iki 15 žmonių. Madoj buvo alus. Alaus užgeria ir dainuos... Seniau dainuodavo liaudiškas, ejjo i šokius - užmiršta ir uždrausta.

Per valstybines šventes pobūvių nebuvo. Vasario 16-ą žmona pasidabins... Kovo 11-ą, Mindaugo - „savy švenčiam“. Birželio 14 kelia vėliavą. Mažai kelia... Ypatingai jaunimas nieko nežino. Žmonos tèvai tremtiniai, ji liko mokykloje. Nedaug ateina žagariečių... Birželi bus Žagarès šventè, vyšniu šventè. Mažai liko tikrų žagaroyšniu... Vežè iš Gorkio vyšnias ir skiepijo ị kaukazines slyvas, rūgščias. Vienas kitas dar turi... Anksčiau su draugais daugiau susitikdavo, senių retėja... Vienas kito privengia, per daug nepasireiškia. (Pasakojo 2010 m. Stanislovas, g. 1932 m. Stungių k. Žagarès seniūnijoje Joniškio r., nuo 1953 m. gyvenantis Žagarèje; baigè Stungiu pradžios mokykla, Žagarès progimnaziją. VSA TT 53.)

Naratyvuose matyti dichotomijos tarp Šiaurès ir Rytų Lietuvos gyventojų. Lietuvè Terese iš Adutiškio, kuri nelaikè savęs „maišyta“, o gyvenime jai teko keltis iš vietos î vieta, manè:

Lietuvè, tèvai lietuviai, šneka lietuviškai tai kaipgi gimtoji kalba. Katalikai... Vertinu sąžiningą darbštumą, gal meilę Tẻvynei... - pagrindiniai. Vertina Lietuvos kultūrą. Svarbu, kas savo, negi vertinsiu gudu ar lenkų... provoslavu papročiai skiriasi.

Valstybines šventes švenčia. Vasario 16-a - svarbiausia. Vèliavas iškelia... Liepos 6-a nelabai man ta šventè. Iškelia vèliavas tremtiniai, ju giminès, kuriems norejjosi Nepriklausomybės, kurie laukè Nepriklausomybės. Masiškai - ne. Dau- giausiai ateina mokytojai ir pensininkai. Pati eina liepos 16-ą i Škaplierinès atlaidus. Būna koncertas.

Tẻveliai nešvęsdavo mūsų kaime - buvo Lenkija, net vèliavų trispalvių nebuvo. Lenkų švenčių valstybinių ar buvo? Tarybų metais atejo îsakymas per Spalio Revoliucijos šventes nedirbti. Gąsdino. Vèliavų neturèjo. Miesteliuose kairieji gal ir iškeldavo. Kaimo žmonès nekèlè - bijojo Sibiro, bijojo būti apkaltinti. Daugiau Vasario 16-ą šventė vokiečiu okupacijos metais pradinejje mokykloje: buvo labai gražu per Vasario 16-ąja, dainavo, deklamavo. Pokary nieko nebuvo - Spalio šventès, Gegužès, Pergalès... Sovietmečiu po karo Vasario 16-ą slaptai švęsdavo partizanų ryšininkai; jie patys ateidavo, pasėdėdavo, pasivaišindavo, kad niekas nežinotų. Nemažai represuotų buvo. Miškuos jaunimas ir pamiškių kaimai. Miesteliuose reikejo pasislèpti. Išejo ir žuvo visi. Žuvo tie, kuriuos areštavo, daug buvo. Adutiškis lenkų metais lietuvybę puoselèjo. Švenčioniu gatvèje gyveno lietuviai, buvo organizuoti... kovojo dèl lietuvių kalbos bažnyčioje... Veikè šv. Kazimiero draugija. Buvo religinė Lietuva. 1939 m. rugsèji sovietai atėjo... Lenku dalis po karo repatrijavo. Lenkų mokykla ir žydu privati mokykla buvo. Lenkų pagrindinè prie bažnyčios. Lenkų mokytojai organizavo lietuvius vaikus, kad Lenkiją mylètų, taptų... (Pasakojo 2010 m. Teresè, g. 1934 m. Bobėnų k. Dysnos apyl. Ignalinos r. Nuo 1962 m. dirbo Adutiškio mokykloje mokytoja; Vilniaus pedagoginiame institute baigė geografijos ir biologijos specialybę. VSA TT 62.)

Adutiškyje, multikultūrinėje erdvèje, kaip Salake, išsiskiria gražios lietuvybės sampratos. Patriotiški naratyvai tiek Elenos iš Salako, tiek ir Teresės iš Adutiškio. Teresè vertina savo kultūra, priešingai negu vietovèse, kur žmonès autochtonai 
gyveno. Tarsi prisiminus Z. Baumaną, politiškai nekontroliuojamų ekonominių jëgu veiksniai ${ }^{34}$ Šiaurès Lietuvoje daro ìtaką „"natūraliems ịpročiams“. „Vietinių“ sąvoka pasieniuose siejama su gyvenamąja vietove.

\section{„SAUGUMO POJŪČIAI" IR NACIONALUMAS}

Išryškèja trys tendencijos, kaip žmonės vertina savo "namus“, kartu priklausomybę tautai ir saugu bendrabūvi pasienio bendruomeneje. Vieni saugiai jaučiasi gyvendami ",tarp savu“". Monsinjoro P. Ščepavičiaus teiginys „,kur gyvenu, čia turètų būti ir mano kapas" rodo, kad savo tapatybę, gyvenimo istorijas ir patirtis jis tapatina su šiais "namais“, kur galiausiai jaučiasi saugus po izvairiu migraciju. Nemaloniausiu patirčiu kentęs, ivairiose politinèse situacijose dirbęs, išgyvenęs, monsinjoras kunigas Pranciškus Ščepavičius šiltai atsiliepia apie žmonių sugyvenimą "tarp savu“. Daug kultūriniu argumentu jis išdėstè kalbẻdamas apie dabartinius "namus“ Aukštaitijoje. Šioje aukštaičiu bendruomenejje „žmonès atsiliepia gana šiltai“ apie įvairių tautybių atstovus. Etniniai konfliktai nenusakomi. Saugumo jausmą sustiprina kultūrinio pasirinkimo galimybès: monsinjoras i̇vardija: „smagu su žemaičiais pasišnekèti žemaitiškai“. Jo priklausymo tautai sampratą trumpai galime laikyti modeliu "tarp savu“", kur ",savi“ tolerantiška prasme yra lietuvių tautos įvairių etniniu grupių žmonès, puoselëjantys lietuvių kalbą ir kultūra, nesusijusią su konkrečia vieta.

Monsinjoro P. Ščepavičiaus sąvoka "tarp savų" pirmiausiai apima žemaičiu istorija, kalbą ir kultūra, taip pat to paties likimo žmones politineje tremtyje Sibire. „Tarp savų“ jis jautèsi saugesnis. Šis fak- tas visiškai susisieja su pradžioje iškeltomis Z. Baumano mintimis, kai kalbama apie migrantų prigimtinès kultūros tradicijas, kurioms reiškiama pagarba siejasi su žmonių saugumu bendruomenèje, telkiančioje nukentëjusius individus "savose justicijose“. Monsinjoras kalba apie griūvančius bendruomenès saitus, kultūrinių „tradicijų" kaitą Aukštaitijoje, tačiau kultūrinių etnografinių skirtumu nesureikšmina. Tremčiu atvejai paženklinti „nesaugumo pojūčiais“, priklausiusiais nuo politinių aplinkybių. Perfrazuojant Z. Baumaną:

nesaugumo šaknys siekia giliai; jos nuskendusios mūsų egzistencijos būsenoje, paženklintos silpnëjančiu saitų tarp žmonių, griūvančiu ir atsitraukiančiu bendruomeniu, tendenciju bendras socialines problemas atkurti nukentejjusiujų individualiuose rūpesčiuose - ir "subsidiarizuoti“ šios kovos uždavinius, paliekant juos troškinti prarastų individų savose justicijose. ${ }^{35}$

Taip pat Vakaru ir Šiaurès Vakaru Lietuvos pasienio teritorijose gyvenančiu žmoniu posakojimai rodo jų saugu gyvenimą "tarp savų". Daugiausia etniniu lietuvių turinčiose bendruomenėse konstruojamos „situacinės“ žmoniu tapatybès ir taikus saugus atvykèlių prisitaikymas prie aplinkos, kuri gal galime laikyti asimiliacija. Ryškiausiu kultūros savitumu ¿vardyta kalba. „Namu“" savokos per daug nesureikšmintos. Galime manyti, 
kad žmonès iš dalies čia gyvena "tarp savų". Vidinès migracijos atvejai turi savų niuansu, palyginti su priverstine , jègos" paveikta migracija svetur, tačiau juos galime priskirti pirmajam modeliui „tarp savų".

Antra tendencija - tai „,situacinès“ pasienio tapatybès, siejamos su izvairių etninių grupių žmonių bendrabūviu „namuose" ir etnografiniu regionu, kuriame puoselejjamos ne tik lietuviškos, o ir autochtonu ar kitos imigravusios etninès grupès „tradicijos“. Žmonès, migravę Lietuvoje toliau ar tremti i Sibira, labai gražiai kalba apie savo gimtinę. „O kaip nebrangi gimtinè..." - sakè Elena iš Salako, gimusi dabartinejje Baltarusijoje, daug migravusi ir buvusi tremtyje Sibire: „kaip brangūs namai, kai išvežè..." Ypač gražių gimtinès, kartu ir „namų" vaizdiniu pateikia žmonès politinių represiju ar priverstinès migracijos paveikti. Ši faktą patvirtina daugelis pasaulio tyrinèto$\mathrm{ju}^{36}$, taip pat mano etnografiniu tyrimu pastebėjimai. Ne mažiau širdingai apie savo „gimtinę, kurią per Antraji pasaulinị karą sudegino vokiečiai, pasakojo rusė moteris iš Miliūnų, gyvenanti netoliese Juodupëje. Ji savo tapatybëje išskyrè religija, o kultūriniai skirtumai jai neimponavo kaip tapatybės ženklai ir ",saugaus bendrabūvio“ garantai. Ji teigè, kad „kokie žmonès yra, su visais sueina... kalba vieną žodį lietuviškai, kitą - rusiškai, sūnus juokiasi, ot pakalbejjo; žmonès tie patys, skiriasi religija".

Šios rusės moters iš Miliūnu atvejis yra įdomus tuo, kad ji save laiko aukštaite "ruse" ir gražiai pasakoja, kokie stačiatikių kultūros papročiai. Netolimo- se teritorijose gyvenančius šeimos narius ji laiko „vietiniais“. „Vietinio“ sąvoką esu užrašiusi Pietryčių Lietuvoje ${ }^{37}$; ji dažniausiai rodè migravusių žmonių saitus su vietos bendruomene, tačiau ne visada sieta su priklausomybe etnografiniam regionui. Vadinasi, kai kurie sėsliau gyvenantys, mažiau migravę kitataučiai žmonès Lietuvos pasienyje save laiko etnografinio regiono gyventojais, kai yra gimę etnografinio regiono teritorijoje, nors laikosi savų kultūrinių „tradicijų". Ši saugaus bendrabūvio idèja, žinoma, gali būti paveikta gražios nacionalinès kultūros politikos. Mano etnografiniu tyrimų duomenimis, ši tendencija būdinga. Tokius požiūrius galime vadinti antruoju modeliu, kai sava įvairiu etniniu grupių kultūra siejama su žmoniu priklausymu multikultūriniam etnografiniam regionui.

Trečia tendencija - pasieniuose gyvenantys žmonės teigia esą ne tik „vietiniai“, bet kartu ir "maišyti“. Du prieštaringi Stanislovo iš Žagarès ir Teresės iš Adutiškio atvejai pabrèžia skirtingą lietuvių nacionalumą ir pagarbą tautinei kultūrai. Mano tyrimų duomenimis, Lietuvoje išgirsime daugiau istoriju, atskleidžiančių naujų žmonių bendrabūvio modelio "mes maišyti“ aspektų. Daugeliu atvejų, šie žmonès turi Lietuvos ar, D. Daukšo teigimu, keletą pilietybių ${ }^{38}$, ar "tarpvalstybinę" tapatybę bei pan. Akivaizdu, kad Lietuvos žmonès, nusakydami savo pilietybę ir "priklausomybę tautai" platesne prasme, savo saugumą iš dalies sieja su vietovès, kurioje gyvena, bendruomene, o kultūros elementai interpretuojami labai ivvairiai. Skirtingu 
etniniu grupių atstovai dažnai įsilieja $\mathfrak{i}$ vietos bendruomenę su savo kultūra, o "tradiciniai“" kultūros elementai interpretuojami. Apibendrindami turime pabrěžti, kad visi trys modeliai rodo žmonių požiūrių tendencijas, tačiau, žinoma, gali būti įvairių kitokių individualiu požiūrių. Hipotezes apie savo „namu“" modelius patvirtina daugiau naratyvu iš Lietuvos pasieniu, o nagrineddami nacionalumo sampratas toliau, ieškosime naujų tendencijų.

\section{IŠVADOS}

Išnagrinèti atvejai iš Lietuvos etnografinių regionų ir pasienių atskleidžia skirtingas žmonių bendrabūvio tendencijas. Visu pirma žmonès jaučiasi saugiai „tarp savu“. Toks modelis paremtas daug migravusio lietuvio tiek Lietuvoje, tiek ir už Lietuvos nuostatomis. Migracija buvo nulemta ,jejgos" - politinių ir darbo aplinkybių. Kultūros regioniškumas šiuo atveju nesureikšminamas, o kultūrinių "tradicijų“ elementai vertinami. Antra ryški „priklausomybès tautai“ tendencija sietina su skirtingų etninių ir etnografinių regionu grupių kultūrine asimiliacija ir savos tautybės išlaikymu. Kai kuriais atvejais šiame antrajame modelyje priklausomybė etnografiniam regionui apibūdinama ne kultūrinėmis tradicijomis, o siejama su "gimtine" ir „namais". Trečioji tendencija - žmonès, kalbėdami apie savo nacionaluma, teigia „esą mišrūnai“. Tokiame modelyje teritorinè priklausomybe siejama su vietove, kurioje gyvenama. „Vietinis“, priklausantis tautai, yra migravęs žmogus, ilgiau gyvenantis kurioje nors kitoje Lietuvos vietoje. Ši samprata užfiksuota Rytu Lietuvos vietovèse, kur istorijoje buvo didesnè migracija ir pan.

Prisiminę P. Kalniaus minti, kad pasienio bendruomenių integraciją stabdo Pietryčiu Lietuvos bendruomenių užda- rumas, turime pabrèžti, kad žmonių bendrabūvis keičiasi. Be to, šiuolaikinejje migracijos eroje dar aiškiai skiriasi istorinių ir politinių aplinkybiu lemtos situacijos Šiaurès, Rytu ir Pietryčiu bei Vakaru Lietuvoje. Multietninè ir multikultūrinè bendruomenẻ Šiaurès Lietuvoje jaučiasi saugesnè negu Rytu Lietuvoje. Pagarba Kito kalbai ir kultūrai, be abejonès, turèjo didelę reikšmę žmoniu "saugumo pojūčiams“ bendraujant. Autochtonai lengviau puoselejjo savo kultūrą ir kartu jautèsi „,saugesni“ multikultūrineje polietninëje aplinkoje. „Tradiciniai“ ir "modernūs“ elementai kultūroje rodo lietuvių prisirišimą prie aplinkos.

Apibendrindami turime sutikti, kad Rytu Lietuvos „,kosmopolitinėse paribių situacijose“, Z. Baumano žodžiais, priešais viduje, t. y. dažniausiai svetimšaliais, laikomi ne tik turintys svetimus ịpročius, bet taip pat gyvenantys už suvereniteto tikrovès $^{39}$ ir kontrolès. Etninių grupiu kultūrinis suverenitetas, jų kalbos ir ,tradicinių" kultūros elementų puoselèjimas lème žmonių saugumo pojūčius ir sutarimą. Nors Z. Baumano teigimu, teoriniu supratimu daugiakultūriškumas degeneruoja í "daugiašališkumo" realybę ${ }^{40}$, Lietuvos pasieniu erdve, priešingai, atskleidžia gražų kultūriniu požiūriu sutariančių etniniu grupių nacionalumą. 


\section{Literatūra ir nuorodos}

${ }^{1}$ Zygmunt Bauman, A Chronics of Crisis 20112016. London: Social Europe Edition, 2017, p. 16.

2 Plačiau žr.: Gunther Schlee, Customary Law and the Joys of Statelessness: Somali Realities beyond Libertarian Fantasies, On Retaliation. Towards an Interdisciplinary Understanding of a Basic Human Condition. Bertram Turner and Gunter Schlee (eds.). New York and Oxford: Berghahn, 2017, p. 208-214; Thomas Hylland Eriksen and Elisabeth Schober, Introduction: The Art of Belonging in an Overheated World, Identity Destabilised: Living in Overheated World. Thomas Hylland Eriksen and Elisabeth Schober (eds.). London: Pluto Press, 2016, p. 1-19.

3 Vida Savoniakaitė, Defining Lithuanians, Lituanus, Volume 60: 4 (2014), p. 17. Terminą „,naratyvų" tapatybė įtikinamai argumentavo Nigel Rapportas, teigdamas, kad šiuolaikinëje visuomenëje objektyvia laikytina žmonių nuomonè apie ju tapatybes, pateikiamas jų pasakojimuose, žr.: Nigel Rapport, Cosmopolitanism: Actors, Relations and Institutions beyond the Communitarian. Amit Vered and Rapport Nigel, Community, Cosmopolitanism and the Problem of Human Commonality. London: Pluto Press, 2012, p. 75-195.

${ }^{4}$ Bauman: „we are made by history while making it, knowingly or not. It is up to us to find answers and give them; in deeds as much as in words", p. 149.

5 Ten pat, p. 18.

6 Ten pat, p. 48.

7 Ten pat, p. 134.

8 Andreas Rauh, Einleitung, Fremdheit und Interkulturalitat: Aspecte kulturele Pluralitat. Andreas Rauh (Hg.). Bielefeld: Transcript Verlag, 2017, p. 7-13.

9 Petras Kalnius, Etniniai procesai Pietryčiu Lietuvoje XX a. antrojoje puseje. Vilnius: Žara, 1998, p. 13.

${ }^{10}$ Irena Regina Merkienė, Prie pirmosios kartos ištakų. Irena Regina Merkienè, Rasa PaukštytèŠaknienė, Vida Savoniakaitė, Žilvytis Šaknys, Pietryčiu Latvijos lietuviai. Vilnius: Versus Aureus, 2005, p. 29.

11 Darius Staliūnas (sud.), Lietuvos erdvinès sampratos ilgajame XIX šimtmetyje. Vilnius: UAB „Baltijos kopa“, 2015.

12 Darius Daukšas, Living in the Borderland: The Case of Polish-Lithuanians, Lituanus, Volume 60: 4 (2014), p. 55.
13 Žr. plačiau: Vida Savoniakaitė, İvadas: ar pažįstame sava ir kita? Savas ir kitas šiuolaikiniais požiūriais. Vida Savoniakaitė (sud.). Vilnius: LII leidykla, p. 11-33.

14 Martin Butler, Paul Mecheril, Lea Brenningmeyer, Introduction, Resistance: Subjects, Representations, Contexts. Martin Butler, Paul Mecheril, Lea Brenningmeyer (eds.). Bielefeld: Transcript Verlag, 2017, p. 7-15.

15 Marcus Rudolf, Casamance Secession: National Narratives of Marginalization and Integration, Politics and Policies in Upper Guinea Cost Societies: Change and Continuity. Christian K. Hojbjerg, Jacqueline Knorr, and William P. Murphy (eds.). New York: Palgrave Macmillan, 2017, p. 187202, 189.

16 Stephen Gudeman\&Chris Hann, Introduction: Self-Sufficiency as Reality and as Myth, Oikos\& Market: Explorations in Self-Sufficiency after Socialism. Stephen Gudeman\& Chris Hann (eds.). New York and Oxford: Berghahn, 2017, p. 1-23, 15.

17 Tyrimuose remiuosi 404 pusiau struktūruotais interviu: LIIBR F73 2342(12-13): Lietuvos istorijos instituto Rankraščiu kolekcija, Vida Savoniakaitè, „Lokalios bendruomenès [Local Communities]“. VSA TT 1-74: Vida Savoniakaitè, Etnografinių rankraščių kolekcija „Lokalios bendruomenès. Tautinis tapatumas [Local Communities: National Identity]".

18 Anne Sigfrid Gronseth, Empathic Relations with Tamil Refugees: Challenging Morality and Calling for Ethic of Knowledge Creation, The Ethics of Knowledge Creation: Transactions, Relations and Persons. Lisette Josephides and Anne Sigfrid Gronseth (eds.). New York and Oxford: Berghahn, 2017, p. 29-48.

19 Ten pat, p. 42-43

20 Anthony P. Cohen, A sense of time, a sense of place: the meaning of case social association in Whalsay, Shetland, Belonging: Identity and Social Organisation in British Rural Cultures. Anthony P. Cohen (ed.). Manchester: Manchester University Press, 1982, p. 21-49. Regioninių procesu tyrimai igavo naujų teorinių aspektų, žr.: Kurt Muhler, Karl-Dieter Opp, Regionl-Nation-Europa. Die Dynamik regionaler und uberregionaler Identifikation. Wiesbaden: VS Verlag fur Sozialwissenschaften, 2006.

21 Andreas Rauh, Einleitung, Fremdheit und Interkulturalitat: Aspecte kulturele Pluralitat. Andreas 
Rauh (Hg.). Bielefeld: Transcript Verlag, 2017, p. 7-13.

22 Franz-Peter Burkund, Von Gasten un Menschenfressern. Zur kulturellen Wahrnehmung von Fremdheit, Fremdheit und Interkulturalitat: Aspecte kulturele Pluralitat. Rauh Andreas (Hg.). Bielefeld: Transcript Verlag, 2017, p. 41-58; Vered Amit and Nigel Rapport, Community, Cosmopolitanism and the Problem of Human Commonality. London: Pluto Press, 2012.

23 Wirth 1938; cit. iš Julie-Anne Boudreau, Global Urban Politics: Informalization of the State. Cambridge: Polity Press, 2017, p. 8.

24 Boudreau, p. 10.

25 Ten pat, p. 105.

26 Bronè Stundžienè teigia, kad iš dainų atkurtini pagrindiniai šeimos naratyvo kontūrai, nagrinejama giminystė; pačiau žr.: Bronè Stundžienè, Šeimos naratyvas dainose: ritualo atodanga ir kintančių kontekstų reikšmė, Tautosakos darbai 51, 2016, p. 156.

27 Judith Schlehe, Lebenswege und Sichtweisen im Ubergang: Zur Einfurung in die interkulturelle Geschlechterforschung, Interkulturelle Geschlechterforschung: Identitaten-Imaginationen-Reprasentationen. Judith Schlehe (Hg.). Frankfurt/New York: Campus, 2001, p. 9-26.

28 Anthony P. Cohen, Belonging: the experience of culture, Belonging: Identity and Social Organisation in British Rural Cultures. Cohen Anthony P. (ed.). Manchester: Manchester University Press, 1982, p. 1-20.

29 Žmonių patriotiškumo, kartu ir nacionalumo šaknys šioje multietninejje Lietuvos teritorijoje, buvusioje Vilniaus gubernijoje, 1919 m. LietuvosVilniaus krašto pasienyje, siekia giliai. $1930 \mathrm{~m}$. minint Vytauto Didžiojo 500 metų jubilieju, Salako tautininkų iniciatyva sklype prie aikštès, kur manyta stovejjus bažnyčią, šalia ten palaidotų žuvusių nepriklausomybės kovų dalyvių buvo pastatytas Nepriklausomybès paminklas, kurị sudare kiek pakeltas ant laiptelių betoninis pjedestalas ir skulptūrinè kompozicija (777 pav.; savamokslis skulptorius M. Farbmanas-Rytvė, kuriam talkino Petras Jasinavičius) žr.: www.salakas.lt [žiūrèta 201711 02]. Etninių grupių bendrabūvio analogiju, kai žmonès gražiai puoselèjo lietuvybę, o îvairių etninių grupių kultūros ,tradicijos" asimiliuojasi, pamatysime Pietryčių Lietuvoje Dieveniškių apylinkių pasienyje. Žr.: Vida Savoniakaitè, Introduction: Belonging on European Borderlands. Jasper Bastian, A Road Not Taken. The Lithuania-Belarus Borderland: A Journey to a Lost Time. Šaltinių rinkinys: autorinis meninių / etnografinių nuotraukų su etnografiniais naratyvais ir komentarais albumas. Dortmund: Buchbinderei Tewes 2017, p. 37-45.

30 Vitalija Stravinskienè, Tarp sugyvenimo ir priešiškumo: tarpetniniai santykiai Rytų ir pietryryčių Lietuvoje (1944-1953), Savas ir kitas šiuolaikiniais požiūriais. Vida Savoniakaitè (sud.). Vilnius: LII leidykla, p. 163-178.

31 Migracijos procesuose atsiranda ,daugkartinių namų“ sampratos, žr. Sabine Strasser, Dynamiken der Deterritorialisierung oder: Wie Bewegung in die Sozialanthropologie kam, Interkulturelle Geschlechterforschung: Identitaten-Imaginationen-Reprasentationen. Judith Schlehe (Hg.). Frankfurt/New York: Campus, 2001, p. 29-51, 46.

32 Rapport, p. 75-195.

33 Bauman, p. 148.

34 Ten pat, p. 146.

35 Bauman: "the roots of insecurity go deep'; they are sunk in our mode of existing, marked by weakening inter-human bonds, the crumbling and falling apart of communities, the tendency to recreate our common social problems into individually suffered worries - and 'subsidiarising' the task of fighting them to the bereaved individuals left to stew in their own justices", p. 146.

36 Heike Drotbohm, Frozen Cosmopolitanism: Coping with Radical Deceleration in Cape Verdean Contexts of Forced Return Migration. Identity Destabilised: Living in Overheated World. Eriksen Thomas Hylland and Schober Elisabeth (eds.). London: PlutoPress, 2017, p. 42-58.

37 Vida Savoniakaité, Šiuolaikiniai dzūkai ir suvalkiečiai. Rasa Paukštytė-Šaknienè, Vida Savoniakaite, Žilvytis Šaknys, Irma Šidiškienè, Lietuvos kultūra: Dzūkijos ir Suvalkijos papročiai. Žilvytis Šaknys (sud.). Vilnius: LII leidykla, 2009, p. 160-161.

38 Daukšas, p. 43-61.

39 Bauman, p. 162.

40 Ten pat, p. 18. 